\title{
Limits of Diagnosis and Molecular Markers for Early Detection of Ulcerative Colitis-Associated Colorectal Neoplasia
}

\author{
Shigehiko Fujii Daisuke Katsumata Takahiro Fujimori \\ Department of Surgical and Molecular Pathology, Dokkyo University School of Medicine, Tochigi, Japan
}

\section{Key Words}

Ulcerative colitis-associated neoplasia, diagnosis •

Surveillance colonoscopy $\cdot$ Molecular marker

\begin{abstract}
The incidence of colorectal neoplasia has been increasing among patients with long-standing and extensive ulcerative colitis (UC), and therefore surveillance colonoscopy has been widely recommended. However, because UC-associated neoplasia is often difficult to detect endoscopically and to discriminate from inflammatory regenerative epithelium histologically, the efficacy of current surveillance remains unsatisfactory. In order to overcome these difficulties, adjunctive modalities for diagnosing UC-associated neoplasia, chromo- and magnifying endoscopy for endoscopic diagnosis and analysis of p53 alteration for histological diagnosis have been introduced. Furthermore, if it were possible to differentiate UC patients with long-standing and extensive colitis into subgroups with a high and a low risk of neoplasia, it would enable physicians to conduct more intensive surveillance with these modalities for patients at higher risk. Several molecular alterations of nonneoplastic epithelium in UC patients with neoplasia may be promising as markers for identifying individuals with UC at increased risk of neoplasia. We evaluated estrogen receptor (ER) methylation of nonneoplastic colorectal epithelium to clarify whether this epigenetic alteration can contribute to the prediction of in-
\end{abstract}

creased neoplasia risk in UC patients and demonstrated that the ER methylation level in nonneoplastic epithelium was higher throughout the colorectum in patients with neoplasia than in those without. These results suggest that analysis of ER gene methylation may be potentially useful for identifying individuals at increased risk of neoplasia among patients with long-standing and extensive UC.

Copyright $\odot 2008$ S. Karger AG, Basel

\section{Introduction}

Patients with ulcerative colitis (UC) show an increased incidence of colorectal neoplasia, and UC-associated colorectal neoplasia represents a major cause of increased mortality in such patients $[1,2]$. In order to improve the prognosis of patients with UC-associated neoplasia, diagnosis at an early or precancerous stage is crucial. Predisposition to colorectal neoplasia in UC is generally considered to depend on 2 risk factors, namely the presence of long-standing disease and extensive colitis [1,3]. Ekbom et al. [1] reported standardized incidence ratios for colorectal cancer risk of 1.7 for patients with proctitis, 2.8 for left-sided colitis and 14.8 for total colitis. A recent meta-analysis reviewed 116 studies of UC-associated colorectal cancer and found that the prevalence of colorectal cancer in patients with UC was $2 \%$ at 10 years, $8 \%$ at 20 years and $18 \%$ at 30 years [3]. Therefore, surveillance

\section{KARGER}

Fax +4161306 1234 E-Mail karger@karger.ch www.karger.com
(C) 2008 S. Karger AG, Basel

0012-2823/08/0775-0002\$24.50/0

Accessible online at:

www.karger.com/dig
Takahiro Fujimori, MD, PhD

Department of Surgical and Molecular Pathology

Dokkyo University School of Medicine

880, Kitakobayashi, Mibu, Shimotsuga, Tochigi 321-0293 (Japan)

Tel. +81 28287 2130, Fax +81 28286 1681, E-Mail t-fuji@dokkyomed.ac.jp 
colonoscopy with multiple random biopsies has been widely recommended for patients with long-standing and extensive UC [4-6]. However, because UC-associated neoplasia is often difficult to detect endoscopically and to discriminate from inflammatory regenerative epithelium histologically, it remains a matter of contention whether conventional surveillance colonoscopy is effective for the early detection of UC-associated neoplasia.

On the basis of these background circumstances, we examine the efficacy of surveillance colonoscopy and its limits for diagnosing UC-associated neoplasia and the use of molecular markers to aid in the identification of individuals at increased risk of neoplasia among patients with long-standing and extensive UC.

\section{Efficacy of Surveillance for UC-Associated Colorectal Neoplasia}

\section{Strategy for Surveillance}

In order to detect UC-associated dysplasia and the early stages of cancer, surveillance colonoscopy has been recommended for patients with long-standing and extensive UC. Current recommendations of surveillance for UC-associated neoplasia are that periodic colonoscopy should begin after a disease duration of 8-10 years for extensive colitis and 15-20 years for left-sided colitis, annual or biannual colonoscopy at regular intervals should be performed, and multiple random biopsy samples should be taken at $10-\mathrm{cm}$ intervals throughout the entire colorectum for histological assessment of neoplasia [5-7]. A histological diagnosis of high- or low-grade dysplasia in flat mucosa, which is often indicative of a concurrent or future cancer, is an absolute indication for colectomy for patients with high-grade dysplasia and should prompt consideration of colectomy in patients with low-grade dysplasia. With regard to protruding lesions, although it remains unsettled how a dysplasia-associated lesion or mass should be differentiated from sporadic adenoma, protruding lesions with a broad-based or carpet-like morphology and surrounding flat dysplasia should be considered dysplasia-associated lesions or masses and require colectomy.

However, in spite of these recommendations, inconsistencies exist in clinical practice. According to a recent survey of British gastroenterologists, only $24 \%$ conducted surveillance colonoscopy in patients with left-sided colitis, only $2 \%$ routinely took more than 20 biopsies, and only $53 \%$ recommended colectomy when high-grade dysplasia was found [8].

Ulcerative Colitis-Associated Colorectal Neoplasia

\section{Efficacy of Surveillance}

Axon [9] and Lynch et al. [10] reviewed 12 studies of surveillance for UC-associated neoplasia published between 1980 and 1993. A total of 92 cancers were reported in 1916 patients who underwent surveillance colonoscopy. Of the 92 cancers, 52 (57\%) were staged as A or B according to Dukes' classification, and the remainder were stage $\mathrm{C}$. Cases defined as stage $\mathrm{C}$ were considered to represent unsuccessful surveillance. Furthermore, numerous subsequent cases at Dukes' stage A or B were likewise judged to have indicated unsuccessful surveillance: cases discovered incidentally during surgery, cases detected by barium enema or sigmoidoscopy, cases without conventional risk factors for neoplasia, duration of UC exceeding 8 years and/or extensive colitis, or cases discovered at the initial colonoscopy in the surveillance program. As a result, only 11 cases (12\%) were considered to represent successful surveillance colonoscopy.

Two investigators have reported clinical studies that compared Dukes' stage and 5-year survival rates between cases with and without surveillance colonoscopy. Choi et al. [11] reported that 19 UC-associated cancers detected by surveillance colonoscopy were at an earlier stage than 22 found during colonoscopy performed following the development of symptoms (Dukes' stages A/B/C: 7/8/4 vs. $3 / 6 / 13$ ). Furthermore, the 5 -year survival rates were higher in patients with surveillance colonoscopy than in those without (77.2 vs. 36.3\%). Similarly, Connell et al. [12] reported a 5 -year survival rate of $87 \%$ for 16 patients in whom cancer developed during surveillance, compared to $55 \%$ for 104 patients who did not undergo surveillance. In another study, Connell et al. [13] reported that surveillance colonoscopy contributed to the detection of cancers in 11 asymptomatic patients. Of those 11 cancers, Dukes' stage was $A$ in $8, B$ in 1 and $C$ in 2 , and no cancer-related deaths occurred during the study period. However, 6 symptomatic cancers (Dukes' stage $\mathrm{C}$ in 4, disseminated in 2) developed during the same period despite surveillance colonoscopy, and 4 of the affected patients died.

In Japan, Hata et al. [14] examined Dukes' stage of patients with and without surveillance colonoscopy and reported that 4 of 5 colorectal cancers found in patients receiving surveillance were Dukes' stage A, whereas 3 of 4 found in patients without surveillance were Dukes' stage $\mathrm{C}$. They pointed out that surveillance would be useful for detecting UC-associated colorectal cancer and may contribute to improvement of the prognosis. We also reviewed Japanese case reports of UC-associated neoplasia published between 1990 and 2002 [15]. Of 118 patients with UC-associated neoplasia, 41 underwent surveillance

Digestion 2008;77(suppl 1):2-12 
Table 1. Clinicopathological features of neoplasias in the surveillance and nonsurveillance groups (adapted from Fujii et al. [15])

\begin{tabular}{lrr}
\hline & $\begin{array}{l}\text { Surveillance } \\
(41)\end{array}$ & $\begin{array}{l}\text { Nonsurveillance } \\
(64)\end{array}$ \\
\hline Depth of neoplastic invasion & & \\
Tis & 11 & 11 \\
T1 & 12 & 5 \\
T2 & 5 & 6 \\
T3 & 10 & 30 \\
T4 & 0 & 6 \\
Unknown & 3 & 6 \\
Lymph node metastasis & & \\
Positive & 4 & 25 \\
Negative & 25 & 23 \\
Unknown & 12 & 16 \\
Liver metastasis, positive & 1 & 4 \\
Peritoneal dissemination, positive & 0 & 7 \\
Dukes' stage & & \\
A & 22 & 15 \\
B & 2 & 8 \\
C & 4 & 25 \\
Unknown & 13 & 16 \\
\hline
\end{tabular}

colonoscopy (surveillance group), 64 did not (nonsurveillance group), and the remaining 13 cases were unknown as to surveillance status. The $64 \mathrm{UC}$-associated neoplasias in the nonsurveillance group were found at colonoscopy for developing symptoms or evaluation of inflammation activity. The depth of neoplastic invasion, the incidence of lymph node metastasis, the incidence of liver metastasis and the stage for the 2 groups are shown in table 1. With regard to the depth of neoplastic invasion, early-stage colorectal cancer, defined as a tumor with Tis and T1, was more frequent in the surveillance group than in the nonsurveillance group (60.5 vs. $27.6 \%$, $\mathrm{p}=0.004)$. The incidence of lymph node metastasis was lower in the surveillance group than in the nonsurveillance group ( 13.8 vs. $52.1 \%, \mathrm{p}=0.002$ ). Of the 5 neoplasias accompanied by liver metastasis, 4 were in the nonsurveillance group. All 7 neoplasias accompanied by peritoneal dissemination were in the nonsurveillance group. With regard to the distribution of Dukes' stages for the 2 groups, stages A, B and C accounted for 22 (78.6\%), 2 (7.1\%) and $4(14.3 \%)$ of the patients in the surveillance group, compared with $15(31.2 \%), 8(16.7 \%)$ and $25(52.1 \%)$ of those in the nonsurveillance group. Indeed, most patients in whom neoplasia was detected during surveillance displayed early-stage cancer. However, despite undergoing periodic colonoscopic surveillance, some patients were unfortunately found to have advanced cancer.

As described, surveillance colonoscopy appears to contribute to the early detection and good prognosis of UC-associated neoplasia, but an appreciable number of cancers were detected at an advanced stage despite surveillance colonoscopy, and many of these cases resulted in less than ideal outcomes. Thus, it still remains questionable whether surveillance colonoscopy with multiple-step biopsy effectively enables the early detection of UC-associated neoplasia.

\section{Limits and Difficulties in Diagnosing UC-Associated Neoplasia}

\section{Endoscopic Diagnosis}

Endoscopically, UC-associated neoplasias at precancerous and early stages show various macroscopic changes [16-18]. Such neoplasias are often flat, plaque-like, superficially elevated or even depressed and frequently appear faintly red, mildly discolored, finely villous and granular. These changes are not clear and are sometimes missed in chronically inflamed epithelium $[19,20]$. For example, figure 1 shows the macroscopic and histological appearances of a case of flat UC-associated neoplasia. In this case, although tubular adenocarcinoma with a mucinous component had massively invaded the submucosa, the neoplasia was flat with the same height as the adjacent nonneoplastic epithelium. We retrospectively verified the percentage of UC-associated neoplasia that was detectable endoscopically before surgical resection. Twenty-two total colectomy specimens were obtained from UC patients who underwent total colectomy because of developing colorectal neoplasia, and a total of 65 UC-associated neoplasias were detected by detailed histological evaluation of the entire resected colorectum in 1999-2006. As shown in figure 2, 30 of 37 dysplasias (81.1\%), 6 of 13 Tis carcinomas (46.2\%) and 2 of 5 T1 (40\%) carcinomas were undetectable endoscopically before surgical resection. Most of the undectable lesions were the flat or flat-elevated type macroscopically. Thus, endoscopic detection of UC-associated neoplasias at the precancerous and early stage appears to be difficult. Therefore, improvements to the current methods of colonoscopy are needed in order to detect UC-associated neoplasias more effectively and accurately.

In the past decade, several Japanese investigators reported that observation of the configuration of the outlet of the colorectal crypt (known as the 'pit pattern') using 

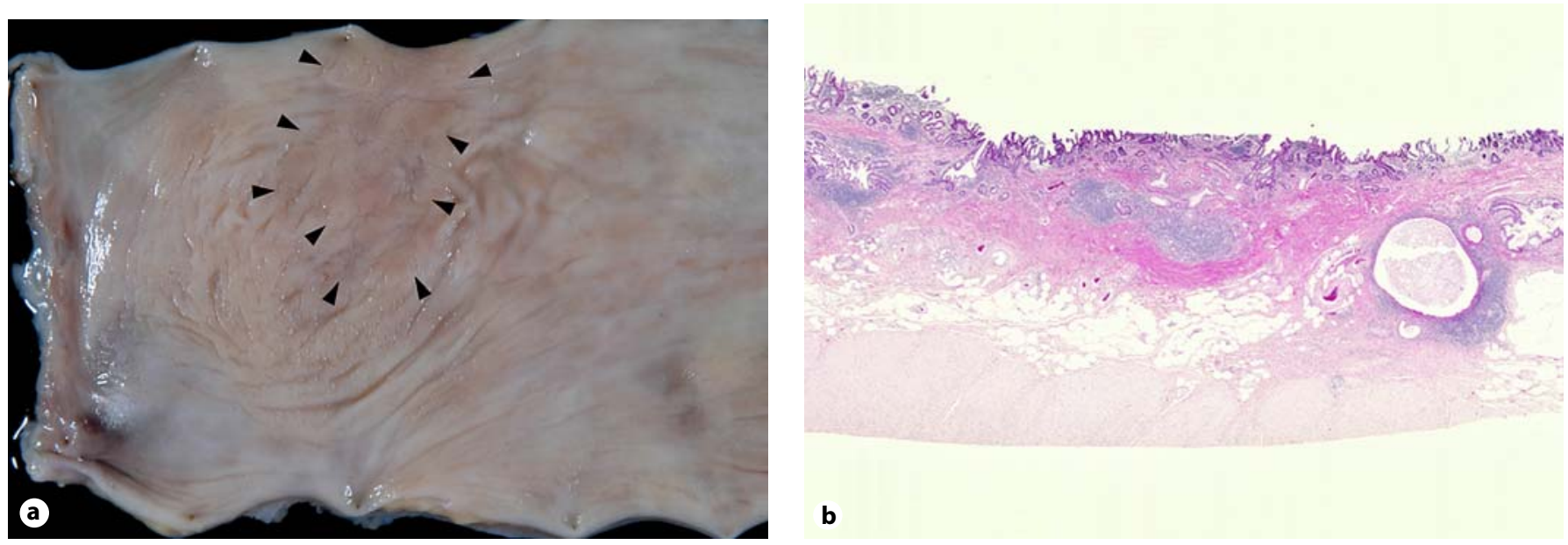

Fig. 1. Flat carcinoma associated with UC. a Macroscopically, the neoplasia appears as a slightly reddish, flat lesion with the same height as the adjacent nonneoplastic epithelium (arrowheads). b Histological appearance shows tubular adenocarcinoma with a mucinous component that has massively invaded the submucosa.

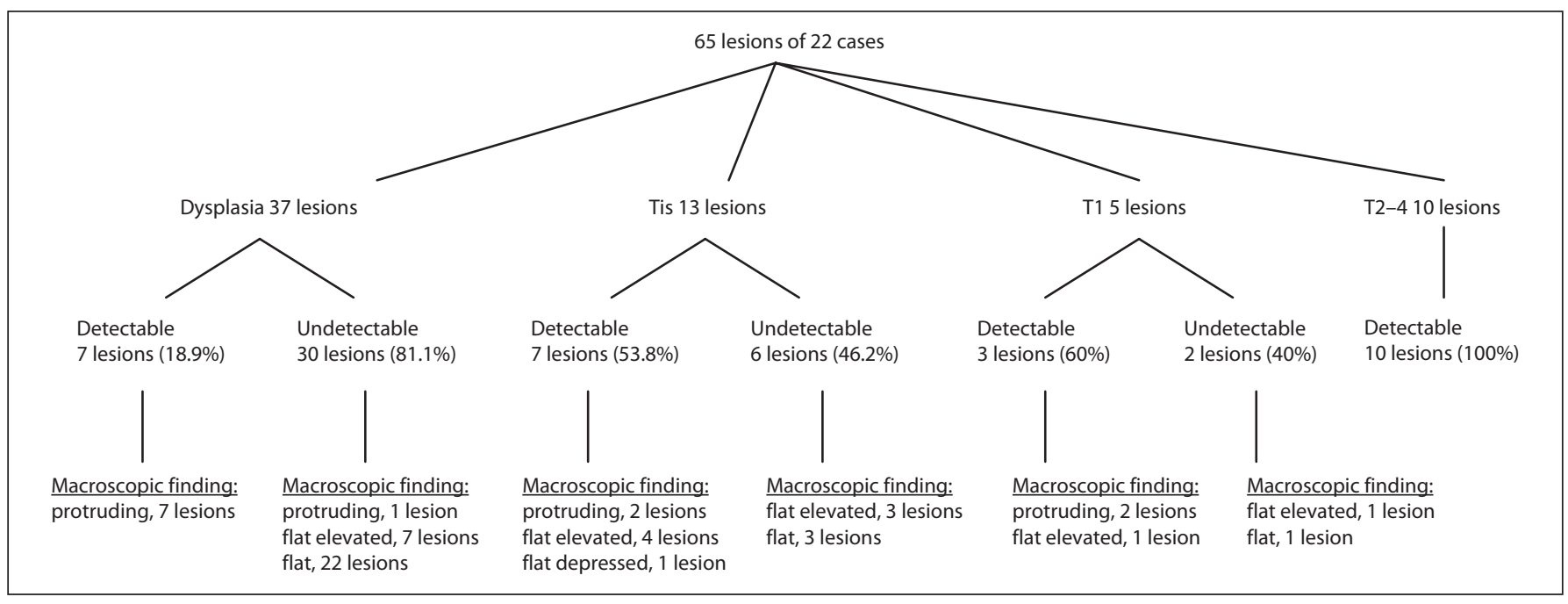

Fig. 2. Percentage of UC-associated neoplasia that was possible to detect endoscopically before surgical resection.

chromo- and magnifying endoscopy is useful for diagnosing and treating sporadic colorectal neoplasia [21,22]. The pit pattern is reported to correlate well with the histological features of the lesions and to aid in the distinction between neoplastic and nonneoplastic changes; type I and II pit patterns are found in nonneoplastic change, whereas types III-V are indicative of neoplastic lesions. According to the WHO classifications, the pit pattern on the surface is thought to predict the histology of sporadic colorectal neoplasia [23]. Likewise, in UC-associated neoplasia, Kiesslich et al. [24] reported the usefulness of chromo- and magnifying endoscopy for detecting UCassociated neoplasia. In a randomized controlled trial to examine whether chromo- and magnifying endoscopy can facilitate the early detection of UC-associated neoplasia, they showed that both the sensitivity and specificity for differentiation between nonneoplastic and neoplastic lesions were 93\% using the pit pattern classification. Their finding suggests that observation of the pit pattern might enable more accurate endoscopic diagnosis 

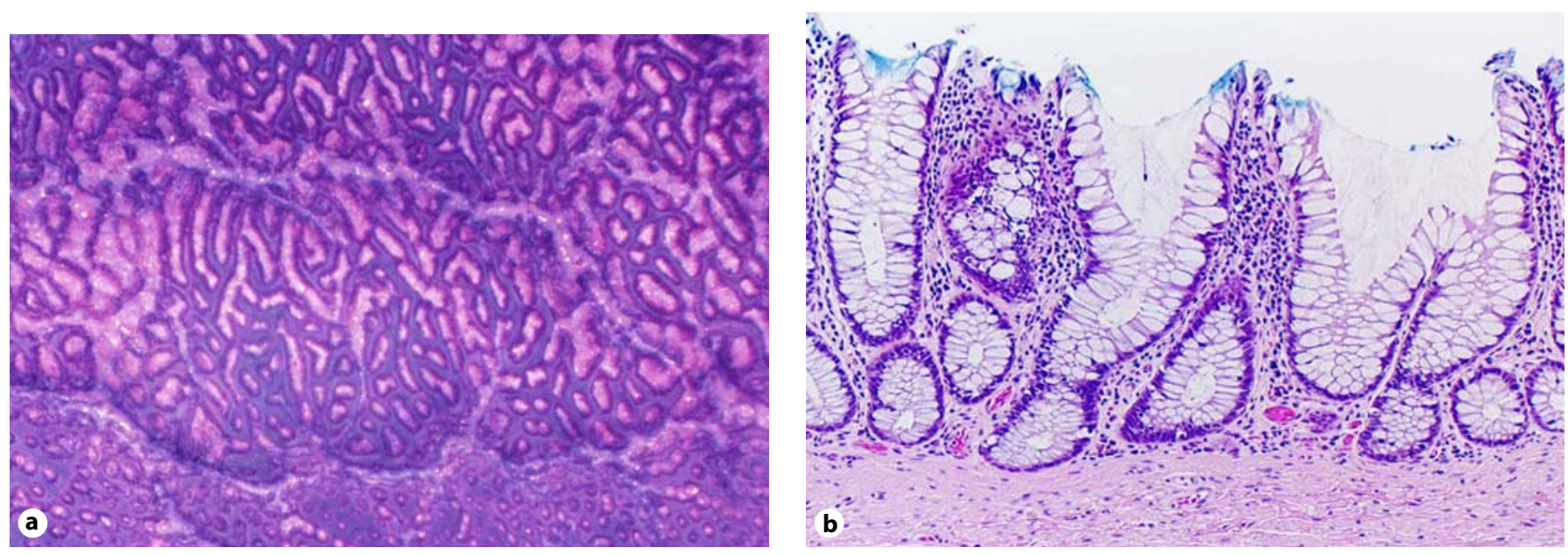

Fig. 3. Stereomicroscopic and histological findings of nonneoplastic epithelium in UC. a Surface microstructure shows club- and/or branch-shaped pits, interpreted as pit pattern III by the pit pattern classification. b The histological appearance of this lesion was hyperplastic epithelium and interpreted as nonneoplastic.

Table 2. The relationship between pit pattern and histological findings for UC-associated neoplasia at the precancerous and early stages (percentages in parentheses)

\begin{tabular}{lcccc}
\hline & \multicolumn{4}{c}{ Configuration of the outlet of the crypt (pit pattern) } \\
\cline { 2 - 5 } & round, oval & club, branch & villous & indeterminate \\
\hline Nonneoplastic $(\mathrm{n}=29)$ & $16(55.2)$ & $11(37.9)$ & $1(3.4)$ & $1(3.4)$ \\
Dysplasia $(\mathrm{n}=6)$ & $2(33.3)$ & $4(66.7)$ & 0 & 0 \\
Carcinoma $(\mathrm{n}=12)$ & $3(25.0)$ & $5(41.7)$ & $2(16.7)$ & $2(16.7)$ \\
\hline
\end{tabular}

of UC-associated neoplasia and more efficient surveillance.

However, other investigators have questioned whether observation of the pit pattern can really contribute to the early and accurate diagnosis of UC-associated neoplasia [25]. We evaluated the relationship between pit pattern and histological findings for UC-associated neoplasia at the precancerous and early stages. As shown in table 2, 11 of 18 UC-associated neoplasias (61.1\%) indeed showed club- and/or branch-shaped pits (interpreted as pit pattern III or IV in the pit pattern classification) and a villous appearance, but an appreciable number of nonneoplastic lesions (11 of $29,37.9 \%$ ) displayed club- and/or branch-shaped pits (fig. 3). Our result suggested that endoscopic diagnosis of UC-associated neoplasia using the pit pattern classification would have a risk of yielding false-positive results. Therefore, it remains unclear whether this method is promising for surveillance colonoscopy. In addition, it is not practical to always use magnifying endoscopy for surveillance. For the moment, as described by Rutter et al. [26], it may be more reasonable to pick up subtle architectural irregularities (inconspicuous lesions) in inflamed colonic mucosa by careful observation using conventional colonoscopy with indigo carmine dye spray. Further studies are needed to determine the potential utility of endoscopic diagnosis using the pit pattern as an adjunctive technique for endoscopically identifying neoplasia in nonneoplastic inflamed epithelium.

\section{Histological Diagnosis}

Similarly to other types of glandular neoplasia, histological diagnosis of UC-associated neoplasia is based on a combination of architectural and cytological alterations. The architectural alterations often result in glandular arrangements, e.g., club-shaped villi, crawling glands or bifid formation at the base of the crypts (fig. 4). The cytological alterations comprise cellular and nuclear pleomorphism, nuclear hyperchromatism, loss of nuclear polarity, marked nuclear stratification, dystrophic goblet 

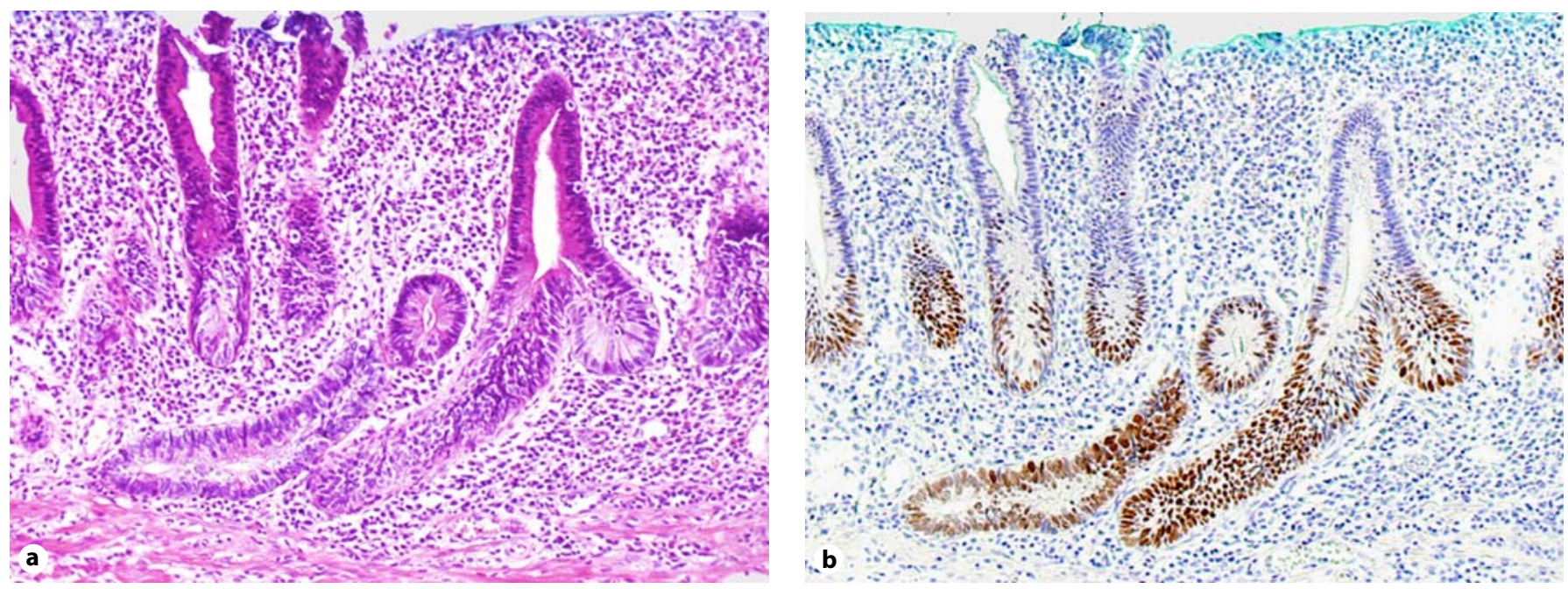

Fig. 4. Crawling gland. a Tubular gland showed crawling and bifid formation at the base of the crypts. b Immunohistochemical analysis showed nuclear accumulation of p53 protein.
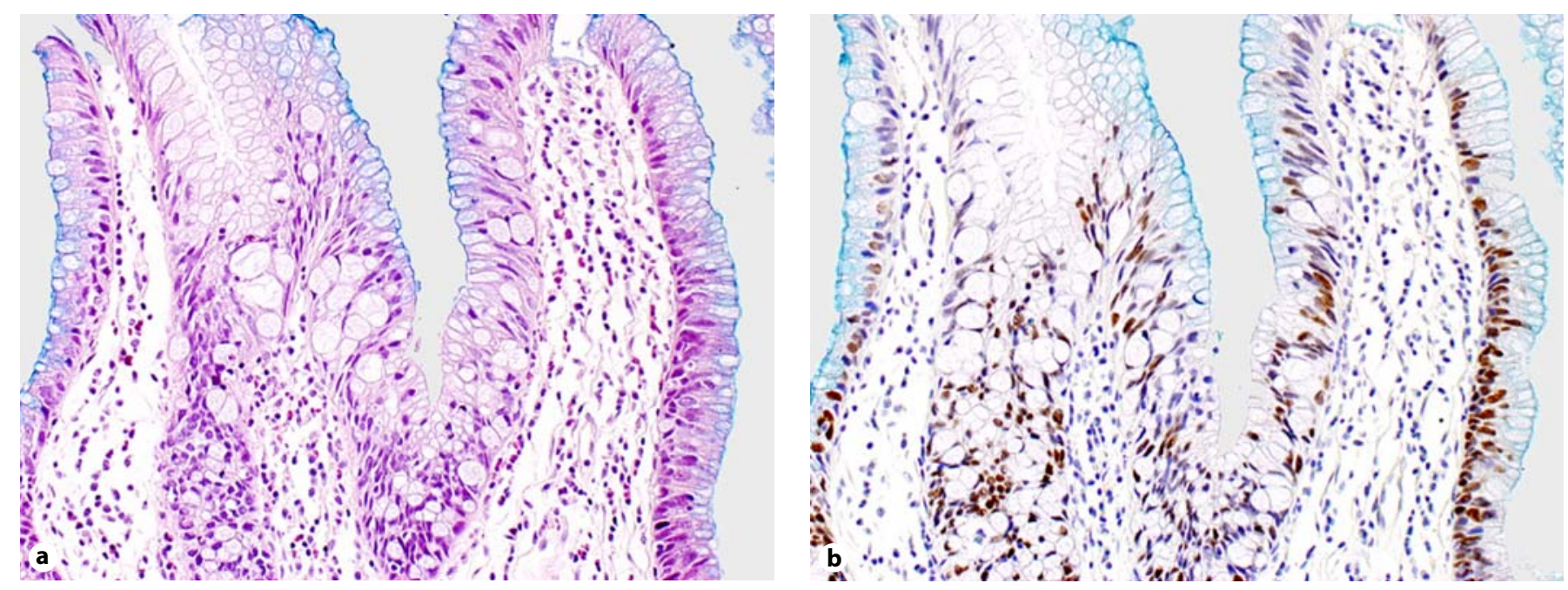

Fig. 5. Dystrophic goblet cell. a Mucin droplets are well preserved but have lost their normal polarity, being present apically or basally or lateral to the nucleus. b Immunohistochemical analysis reveals cells in the lower two thirds of the crypts showing nuclear accumulation of p53 protein.

cells (fig. 5) and failure of maturation from the crypt base to the surface. However, because these alterations are often unremarkable and are limited to the lower two thirds of the crypt, diagnosis of neoplasia, particularly dysplasia, is difficult due to the recurrent and persistent inflammatory change associated with UC. Furthermore, additional difficulties result from specific histological features of UC-associated neoplasia, including neoplasia involving only 1 part of the crypt, neoplasia involving a few crypts in the epithelium and distribution of neoplasia throughout the inflamed epithelium [4]. Therefore, it is not unusual for pathologists to be unable to discriminate between UC-associated neoplasia and inflammatory regenerative epithelium using biopsy specimens stained with hematoxylin and eosin. Furthermore, different pathologists may use different diagnostic criteria to deter- 

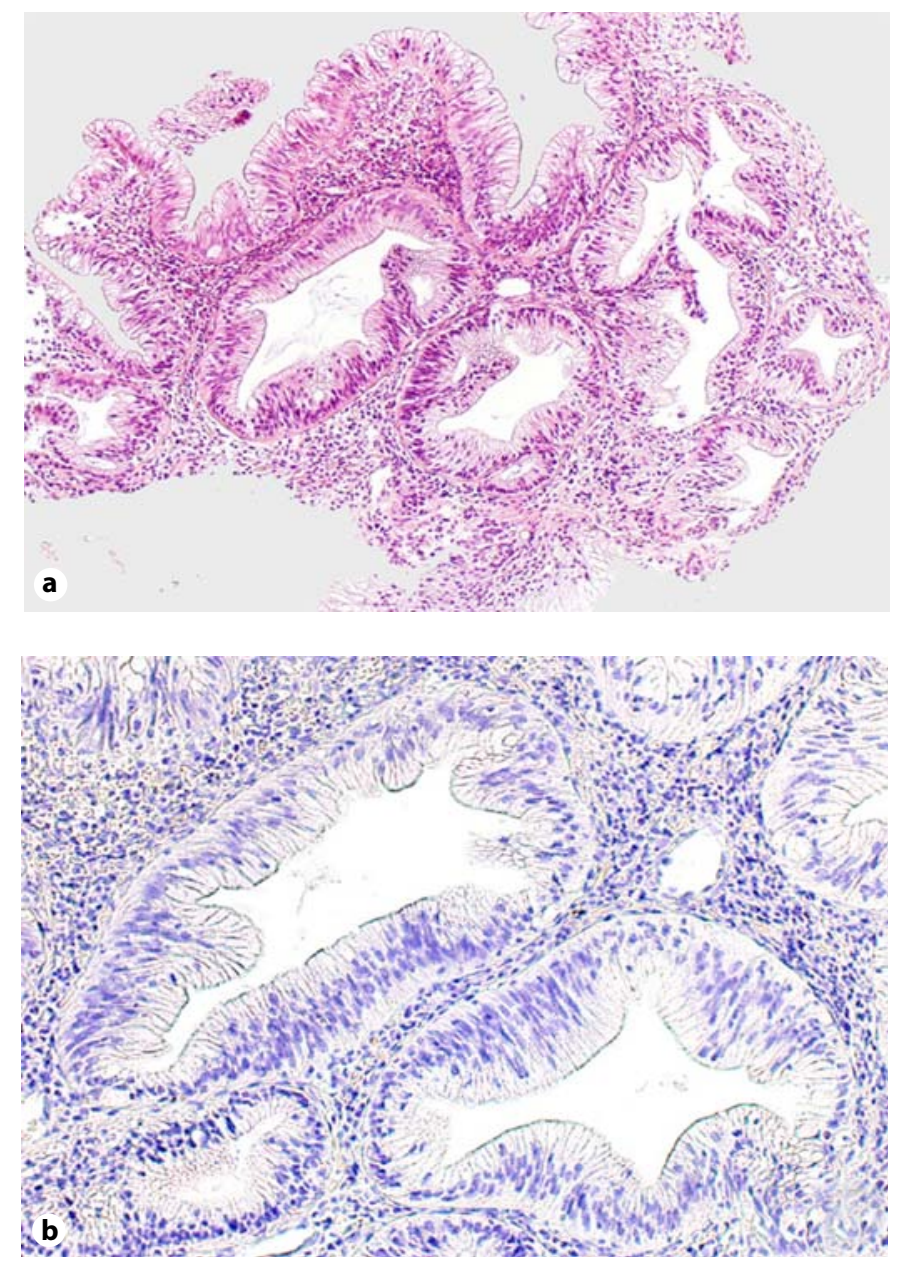

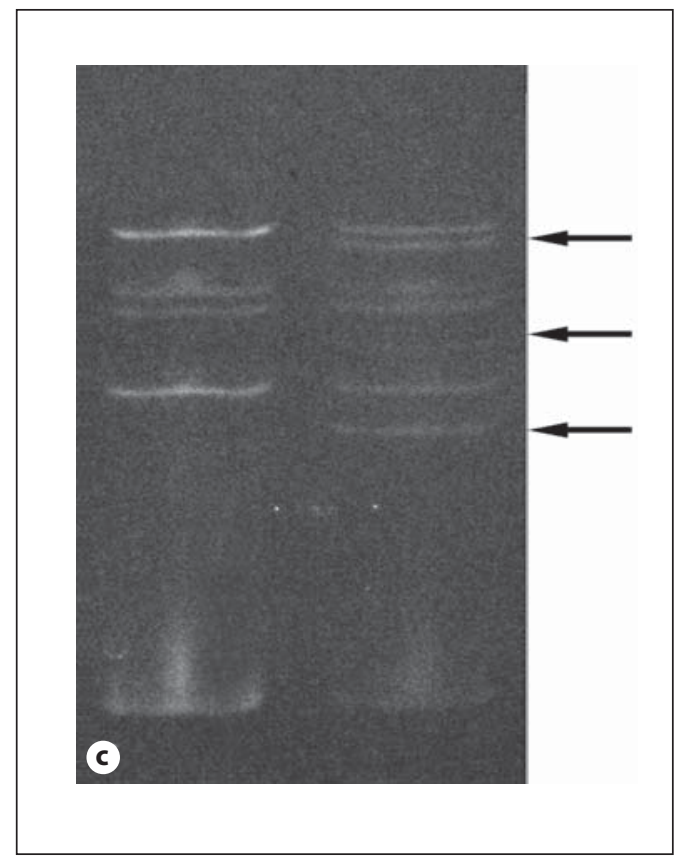

Fig. 6. Dysplasia accompanied by long-standing and extensive UC. a Hematoxylin and eosin staining of neoplasia. $\mathbf{b}$ Immunohistochemical analysis for $\mathrm{p} 53$ shows no nuclear accumulation of $\mathrm{p} 53$ protein. c PCR single-stranded conformation polymorphism analysis of $\mathrm{p} 53$ gene exon 7 shows a mobility shift (arrows) interpreted as positivity for p53 mutation. mine neoplasia $[27,28]$. If dysplasia is detected histologically, a second gastrointestinal pathologist should review the biopsies. In order to improve the accuracy of pathological diagnosis, modalities other than those currently available with conventional techniques are required.

Several reports have shown that the rate of p53 gene alteration is high in UC-associated neoplasia, suggesting that p53 gene alteration represents an early event in the development of UC-associated neoplasia [29-32]. Thus, if it were not possible to discriminate neoplasia from regenerative epithelium in histological diagnosis, such molecular analysis would contribute to accurate pathological diagnosis of UC-associated neoplasia. Immunohistochemical analysis of $\mathrm{p} 53$ protein is a useful and easy method for detecting p53 gene alterations. In our study, 59.5\% (25 of 42) of the neoplastic lesions (dysplasia and carcinoma) and $40.0 \%$ of the lesions that were indefinite for dysplasia displayed nuclear accumulation of p53 protein (fig. 4, 5)
[32]. Thus, immunohistochemical analysis of $\mathrm{p} 53$ would be a useful marker of UC-associated neoplasia in cases where discrimination between neoplasia and regenerative epithelium is difficult. However, negative staining for $\mathrm{p} 53$ protein does not always indicate normality of the p53 gene. When the p53 gene has a nonsense mutation or frameshift, the p53 protein does not accumulate in the nucleus despite the alteration. In fact, 92.9\% (13 of 14 lesions) of the neoplastic lesions that displayed negative immunohistochemical staining for $\mathrm{p} 53$ protein demonstrated a p53 mutation within exons 5-8 under PCR singlestranded conformation polymorphism (fig. 6). This suggests that screening for p53 mutation using PCR single-stranded conformation polymorphism is more accurate than immunohistochemistry for discriminating between UC-associated neoplasia and regenerative epithelium. This technique should be adopted for accurate pathological diagnosis of UC-associated neoplasia. 


\section{Molecular Markers for Identifying Individuals with UC at Increased Risk of Neoplasia}

\section{Requirement for Means of Identifying Individuals at} Increased Risk of Neoplasia

As mentioned above, studies examining the efficacy of surveillance in UC have produced conflicting results and have suggested that surveillance achieves detection of early-stage neoplasia in only a minority of patients and cannot guarantee cancer detection at a curable stage. Such unsatisfactory efficacy of current surveillance colonoscopy for the early detection of UC-associated neoplasia can be attributed to difficulties in the endoscopic and histological diagnoses of UC-associated neoplasia at an early stage. In order to overcome such difficulties, adjunctive diagnostic modalities such as chromoendoscopy for identifying neoplasia in nonneoplastic inflamed epithelium and analysis of p53 alteration for distinguishing neoplastic lesions from regenerative epithelium have been reported. However, it would be impractical to perform these adjunctive modalities for surveillance of all UC patients with long-standing and extensive colitis because of their laborintensive nature and expense. If it were possible to distinguish high- and low-risk subgroups of UC patients with long-standing and extensive colitis, it would enable physicians to conduct more intensive surveillance with these modalities, chromoendoscopy and analysis of p53 alteration, for patients at higher risk of colorectal neoplasia.

\section{Molecular Alterations in Nonneoplastic Epithelium}

Numerous reports have revealed molecular alterations (e.g., p53 mutation, DNA aneuploidy, chromosomal instability, K-ras mutation, p16 hypermethylation, p14 hypermethylation, microsatellite instability, age-related methylation, telomere length shortening, gene expression by DNA microarray) of nonneoplastic epithelium in UC patients with neoplasia [33-42]. Several of these reports have indicated higher frequencies of molecular alterations to nonneoplastic epithelium in UC patients with neoplasia than in nonneoplastic epithelium in UC patients without neoplasia, suggesting that these molecular alterations may be applicable as new markers for identifying individuals with UC at increased risk of neoplasia.

\section{Age-Related Methylation in Colorectal Epithelium}

In several neoplasias, aberrant methylation of promoter region $\mathrm{CpG}$ islands, as an epigenetic modification of DNA, is associated with transcriptional inactivation of tumor suppressor genes and plays a crucial role in the development and progression of neoplasia. In normal colorectal epithelium, some genes are methylated with aging, and this alteration is known as age-related methylation. Issa et al. [43] reported that methylation of the estrogen receptor (ER) CpG island increased with age in nonneoplastic colorectal epithelium and that the same methylation occurred in most sporadic colorectal neoplasias. They concluded that methylation of the ER gene in aging colorectal epithelium could represent one of the earliest events predisposing to sporadic colorectal tumorigenesis.

In UC-associated neoplasia, Issa et al. [40] first reported that the ER and MYOD and CSPG2 genes and p16 gene exon 1, which are affected by age-related methylation in colorectal epithelium, were intensively methylated in neoplastic epithelium from patients with high-grade dysplasia/cancer with UC. Furthermore, they showed that these genes were highly methylated in nonneoplastic epithelium from UC patients with high-grade dysplasia/cancer compared with nonneoplastic epithelium from UC patients without neoplasia. They suggested that age-related methylation could be used as a molecular marker for identifying individuals with UC at increased risk of developing neoplasia, although they made no mention of methylation status by region in the colorectum. Therefore, in our recent study, we analyzed ER gene methylation in multiple samples taken from 6 regions throughout the colorectum: the rectum, sigmoid colon, descending colon, transverse colon, ascending colon and cecum $[44,45]$.

\section{Methylation Analysis of ER Gene in Nonneoplastic \\ Colorectal Epithelium from UC Using Combined \\ Bisulfite Restriction Analysis}

In an attempt to clarify whether methylation analysis of the ER gene in nonneoplastic epithelium can help predict an increased risk for UC-associated neoplasia, we evaluated the ER methylation status of nonneoplastic colorectal epithelia from 18 patients with long-standing and extensive UC, including 8 patients with and 10 without neoplasia. In all patients, multiple nonneoplastic colorectal epithelia were taken from 6 regions of the colorectum, then the methylation status was estimated quantitatively using laser capture microdissection and the combined bisulfite restriction analysis method. Briefly, genomic DNA was treated with sodium bisulfite, and modified DNA was amplified using a specific primer for the ER promoter region. After amplification, the PCR products were digested with the restriction enzyme BstUI. The restriction products were visualized by $6 \%$ PAGE, and the methylation-specific bands were quantified as methylation levels by densitometry (fig. 7). 
Fig. 7. Combined bisulfite restriction analysis for the ER gene in each region of the colorectum. Representative samples of nonneoplastic epithelia from patients with (a) and without (b) neoplasia. $\mathrm{N}=\mathrm{Un}$ methylated breast cancer cell line MCF-7; $\mathrm{P}=$ methylated colon cancer cell line DLD$1 ; \mathrm{R}=$ rectum; $\mathrm{S}=$ sigmoid colon; $\mathrm{D}=\mathrm{de}-$ scending colon; $\mathrm{T}=$ transverse colon; $\mathrm{A}=$ ascending colon; $\mathrm{C}=$ cecum. (Adapted from Tominaga et al. [45].)

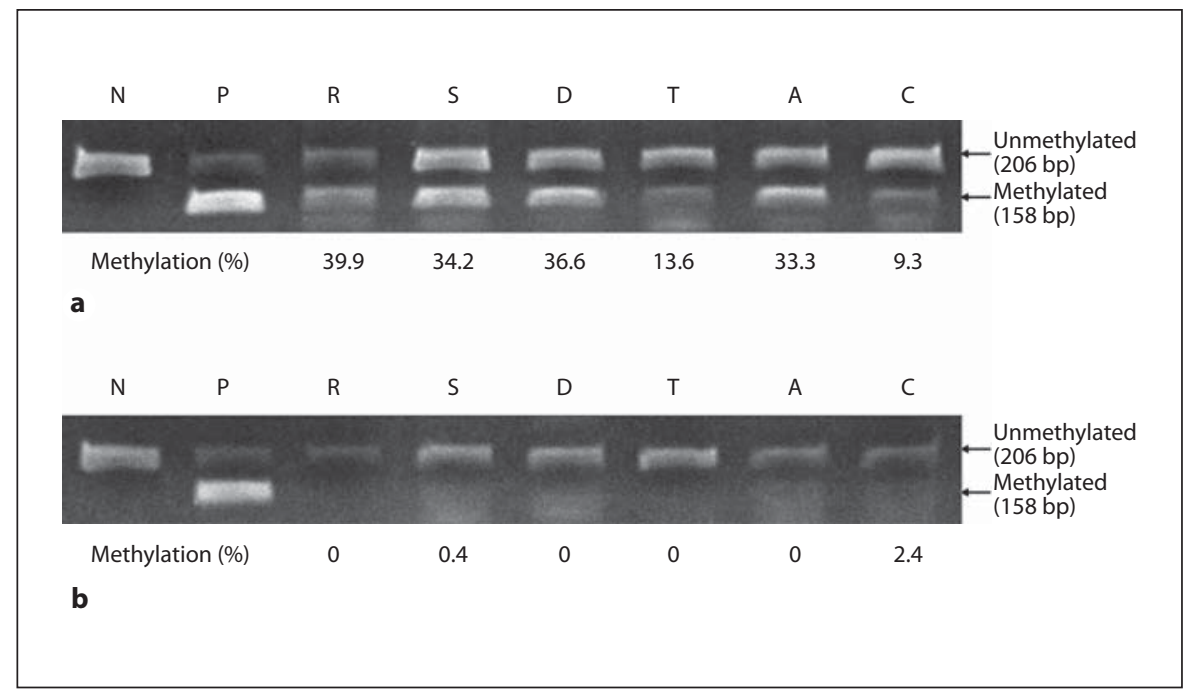

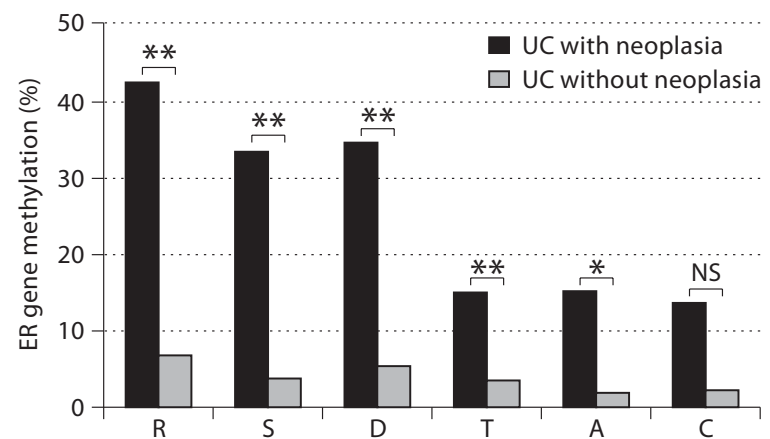

Fig. 8. Average degree of ER methylation in nonneoplastic epithelium from UC patients with and without neoplasia in each region of the colorectum. In the rectum, sigmoid colon, descending colon, transverse colon and ascending colon the average ER methylation in UC patients with neoplasia was significantly higher than in those without neoplasia. ${ }^{* *} \mathrm{p}<0.001,{ }^{*} \mathrm{p}<0.05$. NS $=$ Not significant; $\mathrm{R}$ = rectum; $\mathrm{S}=$ sigmoid colon; $\mathrm{D}=$ descending colon; $\mathrm{T}=$ transverse colon; $\mathrm{A}=$ ascending colon; $\mathrm{C}=$ cecum. (Adapted from Tominaga et al. [45].)

The mean $( \pm \mathrm{SD})$ methylation level of the ER gene was $25.4 \pm 17.8 \%$ in nonneoplastic epithelia from UC patients with neoplasia, whereas it was only $4.0 \pm 6.4 \%$ in that from patients without neoplasia. It was noteworthy that the mean degree of ER methylation in the nonneoplastic epithelium was higher in the patients with neoplasia than in those without $(p<0.001)$. The mean $( \pm$ SD)
ER gene methylation level in each region of the colorectum is shown in figure 8. In UC patients with neoplasia, the ER gene showed increased methylation levels over a widespread area of nonneoplastic colorectal epithelium, and the ER gene methylation in the UC patients with neoplasia was significantly higher than that in the UC patients without neoplasia in all regions of the colorectum except for the cecum (rectum: $42.2 \pm 16.9 \%$ vs. $6.9 \pm$ $8.9 \%, \mathrm{p}<0.001$; sigmoid colon: $33.2 \pm 13.6 \%$ vs. $3.8 \pm$ $4.9 \%, \mathrm{p}<0.001$; descending colon: $32.4 \pm 14.1 \%$ vs. 5.4 $\pm 7.5 \%, \mathrm{p}<0.001$; transverse colon: $15.0 \pm 9.6 \%$ vs. 3.6 $\pm 7.8 \%, \mathrm{p}<0.05$; ascending colon: $15.2 \pm 11.3 \%$ vs. 1.7 $\pm 2.6 \%, \mathrm{p}<0.05$; cecum: $13.6 \pm 20.4 \%$ vs. $2.3 \pm 3.3 \%$, NS).

In this study, we have shown that the ER gene methylation level in nonneoplastic epithelium is higher in UC patients with neoplasia than in UC patients without neoplasia. Furthermore, these epigenetic alterations occurred in both nonneoplastic epithelia of UC patients with carcinoma and in UC patients with dysplasia. These results suggest that an increase in age-related methylation may precede or be a relatively early event in UC-associated tumorigenesis. Therefore, analysis of ER gene methylation in the nonneoplastic colorectal epithelium of UC patients may have potential usefulness for identifying individuals at increased risk of neoplasia from among patients with long-standing and extensive UC. In addition, in UC patients with neoplasia, high levels of ER gene methylation were detected not only in regions in which neoplasia was located but also in other regions widely scattered throughout the colorectum, suggesting that 
analysis of a single biopsy sample (for example, rectal biopsy) may suffice to identify higher-risk patients and that a large number of biopsy samples and total colonoscopy may not always be necessary.

\section{Conclusion}

In this review, we have discussed the efficacy of surveillance colonoscopy for UC-associated neoplasia, critical problems related to the diagnosis of UC-associated neoplasia and molecular markers that can be used to identify individuals with UC at increased risk of neoplasia. Current surveillance colonoscopy remains unsatisfactory, due to difficulties with endoscopic and histological diagnosis of UC-associated neoplasia. These difficulties may be overcome by introducing adjunctive techniques for diagnosing UC-associated neoplasia, analysis of p53 gene alteration and/or chromoendoscopy. However, it seems impractical for all UC patients with conventional risk factors, long-standing disease and extensive colitis to undergo close surveillance colonoscopy using such techniques. In order to realize the full potential of close surveillance colonoscopy, higher-risk groups must be selected from among patients with long-standing and extensive UC. Analyses of age-related methylation in nonneoplastic epithelium may allow identification of such higher-risk patients, and further studies are needed to determine the potential utility of these analyses for practical application.

\section{Acknowledgements}

The Japanese Gastroenterological Association convened core symposiums, 'Problems at the Clinical and Pathological Tangent Point; IBD Cancer' in the 1st annual meeting of the Japanese Gastroenterological Association (January 2005 in Nagoya) and 'Problems at the Clinical and Pathological Tangent Point; Patient Conditions/Treatment and Pathological Diagnosis for IBD' in the 2nd annual meeting (February 2006 in Tokyo). This manuscript summarized our presentation, of which the subject was 'Limits in Diagnosing UC-Associated Colorectal Neoplasia and Methylation of the Estrogen Receptor Gene in Non-Neoplastic Epithelium as a Marker of Colorectal Neoplasia Risk in UC' read in the 1st annual meeting. The authors greatly thank Dr. M. Ito (Nagoya City University, Department of Internal Medicine and Bioregulation, chairman of the 1st annual meeting of the Japanese Gastroenterological Association) and Dr. A. Terano (Dokkyo University School of Medicine, chairman of the 2nd annual meeting) for their help in organizing the core symposiums.

The authors thank Dr. S. Kameoka and Dr. M. Itabashi (Department of Surgery II, Tokyo Women's Medical College), Dr. B. Iizuka (Institute of Gastroenterology, Tokyo Women's Medical College), Dr. H. Mitooka (Division of Gastroenterology, Kobe Kaisei Hospital), Dr. T. Tanaka (Division of Gastroenterology, Shizuoka City Shizuoka Hospital) and Dr. N. Kitajima (Division of Gastroenterology, Kasai City Hospital) for kindly supplying the tissue materials. The authors greatly thank Ms C. Sato-Matsuyama, A. Shimizu, T. Ohtsuki, M. Katayama, S. Miyahara (Department of Surgical and Molecular Pathology, Dokkyo University School of Medicine) for technical assistance.

\section{Disclosure Statement}

The authors declare that no financial or other conflict of interest exists in relation to the content of the article.

\section{References}

1 Ekbom A, Helmick C, Zack M, Adami HO: Ulcerative colitis and colorectal cancer: a population-based study. N Engl J Med 1990; 323:1228-1233.

-2 Langholz E, Munkholm P, Davidsen M, Binder V: Colorectal cancer risk and mortality in patients with ulcerative colitis. Gastroenterology 1992;103:1444-1451.

3 Eaden JA, Abrams KR, Mayberry JF: The risk of colorectal cancer in ulcerative colitis: a meta-analysis. Gut 2001;48:526-535.

4 Riddell RH, Goldman H, Ransohoff DF, Appelman HD, Fenoglio CM, Haggitt RC, Ahren C, Correa P, Hamilton SR, Morson $\mathrm{BC}$, et al: Dysplasia in inflammatory bowel disease: standardized classification with provisional clinical applications. Hum Pathol 1983;14:931-968.
Kornbluth A, Sachar DB; Practice Parameters Committee of the American College of Gastroenterology: Ulcerative colitis practice guidelines in adults (update): American College of Gastroenterology, Practice Parameters Committee. Am J Gastroenterol 2004; 99:1371-1385.

6 Farrell RJ, Peppercorn MA: Ulcerative colitis. Lancet 2002;359:331-340.

7 Itzkowitz SH, Present DH; Crohn's and Colitis Foundation of America Colon Cancer in IBD Study Group: Consensus conference: colorectal cancer screening and surveillance in inflammatory bowel disease. Inflamm Bowel Dis 2005; 11:314-321.

8 Eaden JA, Ward BA, Mayberry JF: How gastroenterologists screen for colonic cancer in ulcerative colitis: an analysis of performance. Gastrointest Endosc 2000;51:123-128.
Axon AT: Cancer surveillance in ulcerative colitis - a time for reappraisal. Gut 1994;35: 587-589.

10 Lynch DA, Lobo AJ, Sobala GM, Dixon MF, Axon AT: Failure of colonoscopic surveillance in ulcerative colitis. Gut 1993;34:10751080.

11 Choi PM, Nugent FW, Schoetz DJ Jr, Silverman ML, Haggitt RC: Colonoscopic surveillance reduces mortality from colorectal cancer in ulcerative colitis. Gastroenterology 1993;105:418-424.

12 Connell WR, Lennard-Jones JE, Williams CB, Talbot IC, Price AB, Wilkinson KH: Factors affecting the outcome of endoscopic surveillance for cancer in ulcerative colitis. Gastroenterology 1994;107:934-944. 
13 Connell WR, Talbot IC, Harpaz N, Britto N, Wilkinson $\mathrm{KH}$, Kamm MA, Lennard-Jones JE: Clinicopathological characteristics of colorectal carcinoma complicating ulcerative colitis. Gut 1994;35:1419-1423.

- 14 Hata K, Watanabe T, Kazama S, Suzuki K, Shinozaki M, Yokoyama T, Matsuda K, Muto T, Nagawa H: Earlier surveillance colonoscopy programme improves survival in patients with ulcerative colitis associated colorectal cancer: results of a 23-year surveillance programme in the Japanese population. Br J Cancer 2003;89:1232-1236.

-15 Fujii S, Fujimori T, Chiba T, Terano A: Efficacy of surveillance and molecular markers for detection of ulcerative colitis-associated colorectal neoplasia. J Gastroenterol 2003; 38:1117-1125.

16 Fujimori T, Miura M, Tonariya Y, Tomita T, Nagasako K: Ulcerative colitis complicated with two colonic carcinomas and precarcinomatous lesions, an autopsy case (in Japanese with English abstract). Stomach Intestine 1980;15:323-330.

17 Tytgat GN, Dhir V, Gopinath N: Endoscopic appearance of dysplasia and cancer in inflammatory bowel disease. Eur J Cancer 1995;31A:1174-1177.

18 Fujii S, Fujimori T, Kashida H: Ulcerative colitis-associated neoplasia. Pathol Int 2002; 52:195-203.

19 Ransohoff DF, Riddell RH, Levin B: Ulcerative colitis and colonic cancer: problems in assessing the diagnostic usefulness of mucosal dysplasia. Dis Colon Rectum 1985;28: 383-388.

20 Sharan R, Schoen RE: Cancer in inflammatory bowel disease: an evidence-based analysis and guide for physicians and patients. Gastroenterol Clin North Am 2002;31:237254.

-21 Rembacken BJ, Fujii T, Cairns A, Dixon MF, Yoshida S, Chalmers DM, Axon AT: Flat and depressed colonic neoplasms: a prospective study of 1000 colonoscopies in the UK. Lancet 2000;355:1211-1214.

-22 Kudo S, Hirota S, Nakajima T, Hosobe S, Kusaka H, Kobayashi T, Himori M, Yagyuu A: Colorectal tumours and pit pattern. J Clin Pathol 1994;47:880-885.

23 Hamilton SR, Rubio CA, Vogelstein B, Sobin LH, Kudo S, Fogt F, et al: Carcinoma of the colon and rectum; in Hamilton SR, Aaltonen LA (eds): World Health Organization Classification of Tumours. Pathology and Genetics of Tumours of the Digestive System. Lyon, IARC Press, 2000, pp 105-119.

-24 Kiesslich R, Fritsch J, Holtmann M, Koehler $\mathrm{HH}$, Stolte M, Kanzler S, Nafe B, Jung M, Galle PR, Neurath MF: Methylene blue-aided chromoendoscopy for the detection of intraepithelial neoplasia and colon cancer in ulcerative colitis. Gastroenterology 2003; $124: 880-888$
25 Hata K, Watanabe T, Motoi T, Nagawa H: Pitfalls of pit pattern diagnosis in ulcerative colitis-associated dysplasia. Gastroenterology 2004;126:374-376.

26 Rutter MD, Saunders BP, Schofield G, Forbes A, Price AB, Talbot IC: Pancolonic indigo carmine dye spraying for the detection of dysplasia in ulcerative colitis. Gut 2004;53. 256-260.

27 Dixon MF, Brown LJ, Gilmour HM, Price AB, Smeeton NC, Talbot IC, Williams GT: Observer variation in the assessment of dysplasia in ulcerative colitis. Histopathology 1988;13:385-397.

28 Eaden J, Abrams K, McKay H, Denley H, Mayberry J: Inter-observer variation between general and specialist gastrointestinal pathologists when grading dysplasia in ulcerative colitis. J Pathol 2001;194:152-157.

29 Yin J, Harpaz N, Tong Y, Huang Y, Laurin J, Greenwald BD, Hontanosas M, Newkirk C, Meltzer SJ: p53 point mutations in dysplastic and cancerous ulcerative colitis lesions. Gastroenterology 1993;104:1633-1639.

30 Harpaz N, Peck AL, Yin J, Fiel I, Hontanosas M, Tong TR, Laurin JN, Abraham JM, Greenwald BD, Meltzer SJ: p53 protein expression in ulcerative colitis-associated colorectal dysplasia and carcinoma. Hum Pathol 1994;25:1069-1074.

-31 Brentnall TA, Crispin DA, Rabinovitch PS, Haggitt RC, Rubin CE, Stevens AC, Burmer GC: Mutations in the p53 gene: an early marker of neoplastic progression in ulcerative colitis. Gastroenterology 1994;107: 369-378.

32 Fujii S, Fujimori T, Chiba T: Usefulness of analysis of p53 alteration and observation of surface microstructure for diagnosis of ulcerative colitis-associated colorectal neoplasia. J Exp Clin Cancer Res 2003;22:107-115.

33 Lashner BA, Shapiro BD, Husain A, Goldblum JR: Evaluation of the usefulness of testing for p53 mutations in colorectal cancer surveillance for ulcerative colitis. Am J Gastroenterol 1999;94:456-462.

34 Holzmann K, Weis-Klemm M, Klump B, Hsieh CJ, Borchard F, Gregor M, Porschen R: Comparison of flow cytometry and histology with mutational screening for $\mathrm{p} 53$ and $\mathrm{Ki}$ ras mutations in surveillance of patients with long-standing ulcerative colitis. Scand J Gastroenterol 2001;36:1320-1326.

35 Rabinovitch PS, Dziadon S, Brentnall TA, Emond MJ, Crispin DA, Haggitt RC, Bronner MP: Pancolonic chromosomal instability precedes dysplasia and cancer in ulcerative colitis. Cancer Res 1999;59:5148-5153.
36 Andersen SN, Lovig T, Clausen OP, Bakka A, Fausa O, Rognum TO: Villous, hypermucinous mucosa in long-standing ulcerative colitis shows high frequency of K-ras mutations. Gut 1999;45:686-692.

37 Hsieh CJ, Klump B, Holzmann K, Borchard F, Gregor M, Porschen R: Hypermethylation of the pl6INK4a promoter in colectomy specimens of patients with long-standing and extensive ulcerative colitis. Cancer Res 1998;58:3942-3945.

38 Sato F, Harpaz N, Shibata D, Xu Y, Yin J, Mori Y, Zou TT, Wang S, Desai K, Leytin A, Selaru FM, Abraham JM, Meltzer SJ: Hypermethylation of the p14(ARF) gene in ulcerative colitis-associated colorectal carcinogenesis. Cancer Res 2002;62:1148-1151.

-39 Brentnall TA, Crispin DA, Bronner MP, Cherian SP, Hueffed M, Rabinovitch PS, Rubin CE, Haggitt RC, Boland CR: Microsatellite instability in nonneoplastic mucosa from patients with chronic ulcerative colitis. Cancer Res 1996;56:1237-1240.

$>40$ Issa JP, Ahuja N, Toyota M, Bronner MP, Brentnall TA: Accelerated age-related $\mathrm{CpG}$ island methylation in ulcerative colitis. Cancer Res 2001;61:3573-3577.

41 O'Sullivan JN, Bronner MP, Brentnall TA, Finley JC, Shen WT, Emerson S, Emond MJ, Gollahon KA, Moskovitz AH, Crispin DA, Potter JD, Rabinovitch PS: Chromosomal instability in ulcerative colitis is related to telomere shortening. Nat Genet 2002;32:280284.

-42 Watanabe T, Kobunai T, Toda E, Kanazawa T, Kazama Y, Tanaka J, Tanaka T, Yamamoto Y, Hata K, Kojima T, Yokoyama T, Konishi T, Okayama Y, Sugimoto Y, Oka T, Sasaki S, Ajioka Y, Muto T, Nagawa H: Gene expression signature and the prediction of ulcerative colitis-associated colorectal cancer by DNA microarray. Clin Cancer Res 2007;13: 415-420.

43 Issa JP, Ottaviano YL, Celano P, Hamilton SR, Davidson NE, Baylin SB: Methylation of the oestrogen receptor $\mathrm{CpG}$ island links ageing and neoplasia in human colon. Nat Genet 1994;7:536-540.

44 Fujii S, Tominaga K, Kitajima K, Takeda J, Kusaka T, Fujita M, Ichikawa K, Tomita S, Ohkura Y, Ono Y, Imura J, Chiba T, Fujimori T: Methylation of the oestrogen receptor gene in non-neoplastic epithelium as a marker of colorectal neoplasia risk in long-standing and extensive ulcerative colitis. Gut 2005;54:1287-1292.

45 Tominaga K, Fujii S, Mukawa K, Fujita M, Ichikawa K, Tomita S, Imai Y, Kanke K, Ono Y, Terano A, Hiraishi H, Fujimori T: Prediction of colorectal neoplasia by quantitative methylation analysis of estrogen receptor gene in nonneoplastic epithelium from patients with ulcerative colitis. Clin Cancer Res 2005;11:8880-8885. 